\title{
Tuft Calcium Spikes in Accessory Olfactory Bulb Mitral Cells
}

\author{
Nathaniel N. Urban ${ }^{1}$ and Jason B. Castro ${ }^{2}$ \\ ${ }^{1}$ Department of Biological Sciences and Center for the Neural Basis of Cognition, Carnegie Mellon University, Pittsburgh, Pennsylvania 15213, and ${ }^{2}$ Center \\ for Neuroscience at the University of Pittsburgh and Center for the Neural Basis of Cognition, University of Pittsburgh, Pittsburgh, Pennsylvania 15260
}

The mammalian accessory olfactory system is critical for the detection and identification of pheromones and the representation of complex stimuli including sex, genetic relatedness, and individual identity. Mitral cells, the principal cells of the accessory olfactory bulb (AOB), receive monosynaptic input from the sensory periphery and already show highly specific response properties, firing selectively for combinations of genetic markers and gender-specific cues. Vomeronasal sensory neuron axons form synapses onto distal tuft-like branches of mitral cell primary dendrites. We have studied dendritic excitability and synaptic integration in AOB mitral cell dendrites, and we show that dendrites of accessory olfactory bulb mitral cells support action potential propagation and can fire regenerative spike-like events that are likely to contribute to the integration of inputs to these cells. These tuft spikes may be important for the specificity of $\mathrm{AOB}$ mitral cell responses.

Key words: pheromone; vomeronasal; dendritic spike; glomerulus; synaptic integration; mitral cell

\section{Introduction}

The accessory olfactory system, consisting of the vomeronasal organ, the accessory olfactory bulb (AOB), and associated brain areas, is critical for detecting (Holy et al., 2000; Leinders-Zufall et al., 2000) and responding to (Del Punta et al., 2002a; Leypold et al., 2002; Stowers et al., 2002) pheromonal cues in many mammals, including mice (Dulac and Torello, 2003). The accessory olfactory system is involved in the determination of sex, genetic similarity, and possibly the identification of specific individuals (Hegde, 2003). Activity of individual mitral cells, the output neurons of the AOB, has been shown in mice to be specific to particular combinations of genetic markers and gender (Luo et al., 2003). Such specificity is likely to require the detection and integration of activity induced by multiple types of pheromones (Holy et al., 2000; Luo et al., 2003). One possible site of this integration is in the dendritic tree of $\mathrm{AOB}$ mitral cells.

Mitral cells of the AOB receive convergent inputs from vomeronasal sensory neurons onto multiple highly branched tufts, which are formed by their primary dendrites (Takami and Graziadei, 1991; Belluscio et al., 1999; Rodriguez et al., 1999). These connections are made in the glomeruli of the AOB. This input to mitral cell tufts represents the only excitatory input these cells are known to receive. The multitufted morphology of AOB mitral cell dendritic arbors has prompted speculation that AOB mitral cells receive information about the presence and/or concentration of multiple pheromones to different regions of their den-

Received Aug. 16, 2004; revised March 31, 2005; accepted April 14, 2005.

This work was supported by the National Institute on Deafness and Other Communication Disorders (R01 DC005798-01 and R21 DC006631-01). We acknowledge Vikrant Kapoor for work on initial simulations, Greg LaRocca for technical support, and Jenny Chan for help with neural reconstructions.

Correspondence should be addressed to Nathaniel N. Urban, Department of Biological Sciences and Center for the Neural Basis of Cognition, Carnegie Mellon University, 4400 Fifth Avenue, Pittsburgh, PA 15213. E-mail: nurban@cmu.edu.

DOI:10.1523/JNEUROSCI.0297-05.2005

Copyright $\odot 2005$ Society for Neuroscience $\quad$ 0270-6474/05/255024-05\$15.00/0 dritic arbor (Belluscio et al., 1999; Luo et al., 2003) (but see Del Punta et al., 2002b) and that detection of coincident inputs contributes to the specificity of mitral cell output. Such an arrangement suggests that the biophysical properties of $\mathrm{AOB}$ mitral cell dendrites will be critical to generating the highly specific responses of AOB mitral cells.

Here, we describe anatomical and physiological properties of the multitufted dendrites of $\mathrm{AOB}$ mitral cells and discuss how active synaptic integration may facilitate the sensitivity of pheromone detection in the AOB. Dendritic arbors of AOB mitral cells have between two and 10 tufts, each of which seems to terminate in a glomerulus. Using calcium imaging, we visualize activation of local regenerative events in single dendritic tufts (tuft spikes). These events can be as large as calcium transients evoked by single backpropagating action potentials (APs) initiated at the soma and are reduced by NMDA receptor (NMDAR) antagonists. The properties of these events suggest that local nonlinear integration of synaptic inputs occurs in $\mathrm{AOB}$ mitral cell tufts and may allow for improved sensitivity and selectivity of mitral cell responses in the AOB.

\section{Materials and Methods}

Slice preparation. Sagittal olfactory bulb slices (300-350 $\mu \mathrm{m}$ thick) were prepared from young mice [postnatal day 14 (P14) to P45, mostly between P21 and P35] as described previously (Urban and Sakmann, 2002). All data shown are from animals aged P21-P35. Similar results were observed from cells from all ages of animals in this range. The olfactory bulb develops early, with mitral cell dendritic morphology at P7 being indistinguishable from adult (Lin et al., 2000). Mice were anesthetized $(0.1 \%$ ketamine $/ 0.1 \%$ xylazine; $\sim 3 \mathrm{mg} / \mathrm{kg}$, i.p. $)$ and decapitated. Olfactory bulbs were cut on a vibratome while submerged in ice-cold oxygenated Ringer's solution containing the following (in mM): $125 \mathrm{NaCl}, 2.5$ $\mathrm{KCl}, 25 \mathrm{NaHCO}_{3}, 1.25 \mathrm{NaH}_{2} \mathrm{PO}_{4}, 1 \mathrm{MgCl}_{2}, 25$ glucose, $2 \mathrm{CaCl}_{2}$. In some cases, $0.5 \mathrm{~mm}$ ascorbate, $1 \mathrm{~mm}$ pyruvate, and $2 \mathrm{~mm}$ myo-inositol were added to the slicing medium.

Electrophysiology. Whole-cell voltage recordings were obtained from the somata of identified AOB mitral cells (Stuart and Spruston, 1995). 


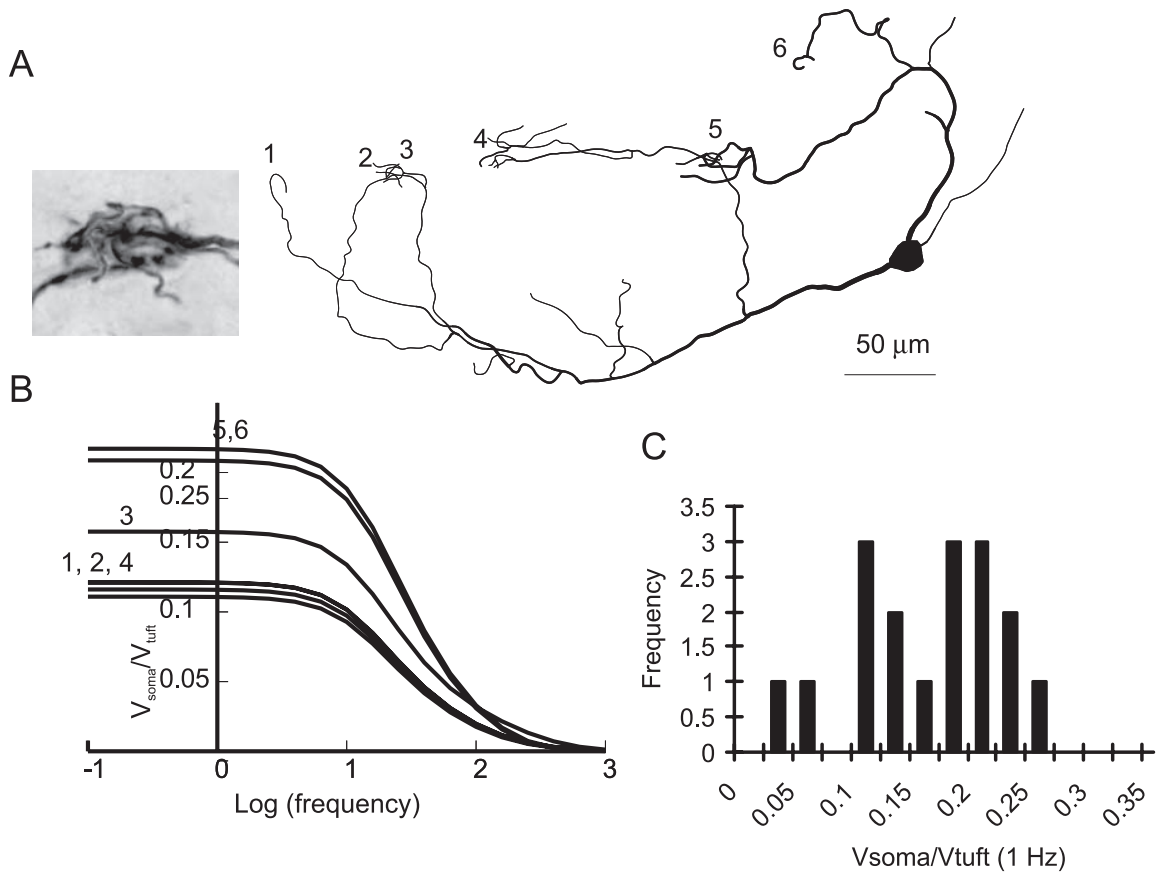

Figure 1. $A O B$ mitral cell tufts are electrically remote from the soma. $A$, Reconstruction of an $A O B$ mitral cell having six tufts terminating in five glomeruli. The inset shows convergence between tufts 2 and $3 . B$, Data from simulations showing the decay of voltage changes from tuft to soma as a function of the frequency of a sinusoidal input (current injection). Each line represents the voltage attenuation from a single tuft of the reconstructed cell shown in $\boldsymbol{A}$ plotted against the frequency of the sine wave. $\boldsymbol{C}$, Histogram of passive attenuation from tuft to soma for 17 tufts from four reconstructed cells simulated in Neuron.

electrodes with $\sim 1 \mu \mathrm{m}$ tip size. Movement of the electrode $20 \mu \mathrm{m}$ away from the visualized tuft eliminated the response in all five experiments in which it was tested, indicating that stimulation was highly localized.

Simulations were performed using Neuron (Hines and Carnevale, 2001). For passive simulations, parameters were $R_{\mathrm{m}}=50,000 \Omega \mathrm{cm}^{2}$, $C_{\mathrm{m}}=1.2 \mu \mathrm{F} / \mathrm{cm}^{2}, R_{\mathrm{i}}=70 \Omega \mathrm{cm}$. These values were observed to give a good fit between simulation results and neuronal data for small hyperpolarizing current pulses and are similar to the values used for many neuron types, including a recent study on $\mathrm{AOB}$ mitral cells (Ma and Lowe, 2004). Data on the degree of attenuation in the passive models as a function of morphology were computed using the impedance tool that is a standard feature of Neuron (Hines and Carnevale, 2001). This tool calculates the degree of attenuation of voltage changes induced by a variable frequency sine wave injected at one site and recorded at a second. Figure $1 B$ shows the ratio of the voltage change at the soma to that in the tuft when current is injected into the tuft. The results obtained using this tool were confirmed by injecting brief and steady-state currents into distal tufts in the model (data not shown).

Data are reported as mean \pm SEM. Significance was assessed by paired or unpaired Student's $t$ tests, as appropriate. All animal care was performed in accordance with the guidelines of Institutional Animal Care and Use Committee

Slices were superfused with oxygenated Ringer's solution containing the following (in mM): $125 \mathrm{NaCl}, 2.5 \mathrm{KCl}, 25 \mathrm{NaHCO}_{3}, 1.25 \mathrm{NaH}_{2} \mathrm{PO}_{4}, 1$ $\mathrm{MgCl}_{2}, 25$ glucose, $2 \mathrm{CaCl}_{2}$, warmed to $34-36^{\circ} \mathrm{C}$. Whole-cell recordings were established using pipettes (resistances of 2-8 $\mathrm{M} \Omega$ ) filled with a solution containing the following (in $\mathrm{mM}$ ): 120 potassium gluconate, 2 $\mathrm{KCl}, 10 \mathrm{HEPES}, 10$ sodium phosphocreatine, $4 \mathrm{MgATP}$, and 0.3 $\mathrm{Na}_{3} \mathrm{GTP}$, adjusted to $\mathrm{pH} 7.3$ with $\mathrm{KOH}$. Calcium imaging was performed on cells filled with calcium orange (100-200 $\mu$; Molecular Probes, Eugene, OR). Voltage was measured in current-clamp mode with Multiclamp 700 amplifiers (Molecular Devices, Union City, CA). Data were filtered $(4 \mathrm{kHz})$ and digitized at $10 \mathrm{kHz}$ using an ITC-18 (Instrutech, Mineola, NY) controlled by custom software written in Igor (WaveMetrics, Lake Oswego, OR). Fluorescence imaging (Margrie et al., 2001) was performed using back-illuminated frame-transfer cameras with either 1 or $10 \mathrm{MHz}$ digitization rate and 17 or $13 \mu \mathrm{m} /$ pixel, respectively (Roper Scientific, Trenton, NJ) on an Olympus Optical (Melville, NY) BX51WI microscope fitted with $20 \times$ and $60 \times$ objectives [imaging area, $\sim 430 \mu \mathrm{m}$ $(17 \mu \mathrm{m}$ pixels at $20 \times)$ or $330 \mu \mathrm{m}(13 \mu \mathrm{m}$ pixels at $20 \times)$ and $110 \mu \mathrm{m}(13$ $\mu \mathrm{m}$ pixels at $60 \times)$, respectively] at $20-50 \mathrm{~Hz}$. Calcium orange was illuminated using a Xenon lamp connected to a power supply (Opti Quip, Highland Mills, NY or TILL Photonics, Munich, Germany) and either a standard rhodamine filter set (excitation, $540 \mathrm{~nm}$ short pass; dichroic, $565 \mathrm{~nm}$; emission, $605 \mathrm{~nm}$ long pass) or the same filter set minus the excitation filter in the case of the TILL Photonics monochromated illuminator. All imaging data shown are from single recorded sweeps without bleaching correction. Calcium transients were measured along lines of interest as shown in the relevant figures. Dashed lines indicate lines used for background subtraction. In all calcium-imaging experiments, high-frequency stimulation (seven or more APs at $40 \mathrm{~Hz}$ ) was used to determine the level at which the calcium dye became saturated. All reported $\Delta F / F$ s were below the saturation range. Biocytin $(2 \mathrm{mg} / \mathrm{ml}$; Sigma, St. Louis, MO) was included routinely in the intracellular solution to allow the morphology of neurons to be analyzed. APV was obtained from Sigma. Reconstructions of mitral cell morphology were performed using Neurolucida (MicroBrightField, Williston, VT).

Extracellular stimulation was delivered using constant-current pulses (100-200 $\mu$ s, up to $1 \mathrm{~mA}$ ) delivered via glass (theta glass or monopolar) of Carnegie Mellon University.

\section{Results}

\section{Morphology and passive modeling}

As a critical first step toward understanding how synaptic responses are integrated by $\mathrm{AOB}$ mitral cells, we reconstructed the morphology of biocytin-filled cells and constructed passive models in Neuron. Visualization (Fig. $1 A$ ) of these cells revealed that these cells had on average $4.4 \pm 0.4$ tufts making synapses in $3.3 \pm 0.5$ different glomeruli $(n=27$ cells). Thus, in most cases, at least one glomerulus was occupied by multiple tufts from the same neuron. These models contained no voltage-dependent channels and were used only to analyze the degree to which inputs to the tuft would be attenuated en route to the soma. Although the assumption that AOB mitral cell dendrites behave in a passive manner is incorrect (Ma and Lowe, 2004) (our results), the analysis of the passive dendritic structure of mitral cells provides a fundamental understanding of the constraints governing dendritic integration in these cells and serves as a starting point for future models of dendritic integration. In simulations from five reconstructed cells having a total of 17 tufts, when current was injected into the tuft, the steady-state voltage change at the soma was $14 \pm 1 \%$ of that at the tuft (Fig. $1 B, C$ ). Thus, in the absence of active propagation of signals, dendrites of AOB mitral cells are highly isolated from the soma. Thus, we next looked for evidence of voltage-dependent channels in the dendrites of $\mathrm{AOB}$ mitral cells.

\section{Backpropagating spike-evoked calcium transients}

Given this degree of electrical isolation of tufts from the soma, we wanted to determine whether voltage-dependent channels in dendrites facilitate the propagation of signals and possibly play a role in the integration of synaptic inputs (Urban and Barrio- 


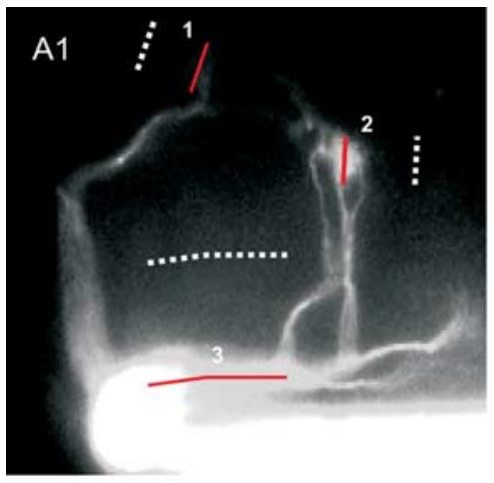

A2
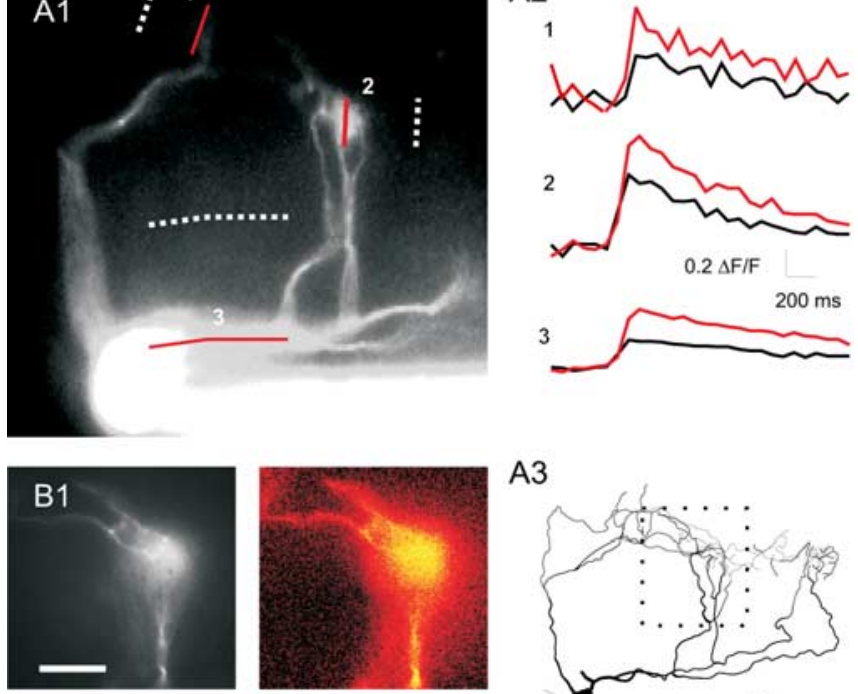

A3

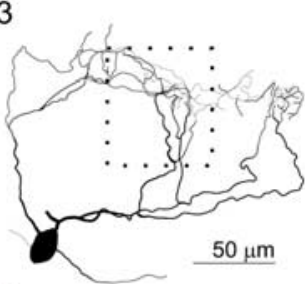

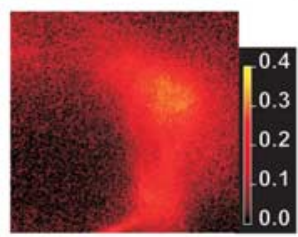

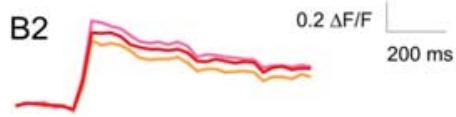

Figure 2. Backpropagation of APs to AOB mitral cell tufts. A1, Fluorescence image (20X objective) of an $A O B$ mitral cell showing multiple dendrites converging on two glomeruli. Solid and dotted lines (1-3) show locations from which calcium transients and background fluorescence were measured in $\boldsymbol{A 2}$. Calcium transients evoked at the locations indicated in $\boldsymbol{A} \boldsymbol{1}$ by single APs (black) or pairs of APs at $40 \mathrm{~Hz}$ (red). $\boldsymbol{A}$, Reconstruction of the cell in $\boldsymbol{A} 1$ including additional tufts (on the right) that were not visible in the fluorescence image. The area imaged in $\mathbf{B} \mathbf{1}$ is indicated by the dotted square. $\boldsymbol{B 1}$, Images $(60 \times)$ of the subregion of the dendrite shown in A3. Two planes of focus are shown (top and bottom rows). Grayscale images show morphology, and color images plot peak $\Delta F / F$ for each pixel in the same focal planes shown on the left. $\Delta F / F$ appears to be uniform throughout all branches that can be observed. B2, $\Delta F / F$ plotted (in corresponding colors) versus time for the three dendrites seen in the bottom row of $\boldsymbol{B}$ 1. Scale bar: (in $\boldsymbol{B 1}) \boldsymbol{A} 1,100 \mu \mathrm{m} ; \boldsymbol{B} 1,50 \mu \mathrm{m}$. The color bar shows values of $\Delta F / F$ for the images in the right column of $B 1$

nuevo, 1998). First, we tested whether AOB mitral cell dendrites contained voltage-dependent channels and whether APs could propagate in these structures by measuring dendritic calcium transients after APs evoked by somatic current injection. As has been reported recently (Ma and Lowe, 2004), single APs evoked by somatic current injection caused calcium influx throughout the primary dendrites of AOB mitral cells (Fig. 2A). AP invasion also was observed in the small branches within the glomerulus (Fig. $2 B$ ). Action potential-evoked tuft calcium transients were larger than somatic calcium transients $(156 \pm 14 \%$; $p<0.05$; paired $t$ test; $n=20$ ). In six cells, multiple branches within the same tuft were examined, and calcium transients were uniform throughout all observable branches within the tuft (average fractional difference between transients in different branches, $10 \pm$ $5 \% ; n=8$ pairs of branches in six cells) (Fig. $2 B$ ). Thus, the primary dendrites of $\mathrm{AOB}$ mitral cells contain calcium channels and propagate APs faithfully from soma to all branches in all tufts. The presence of voltage-gated channels in these dendrites suggests that inputs to mitral cell tufts may be boosted en route to the soma, allowing them to overcome their passive electrical isolation.

\section{Synaptically evoked calcium transients}

We next investigated propagation of synaptic inputs from the tuft to the soma. After cells were filled with fluorescent calcium dye via a somatic patch pipette, a glass stimulation electrode was placed in the glomerulus, where a fluorescent tuft was visualized (Fig. 3A1). The position of the electrode tip was adjusted until a low-amplitude stimulus elicited an EPSP in the mitral cell being recorded. The voltage response and calcium transients observed in most mitral cells varied with the intensity of the stimulus current used. At low stimulation intensities, small EPSPs but no calcium transients were observed. Increasing the stimulation intensity caused larger EPSPs and calcium transients that were restricted to the tuft closest to the stimulation electrode (Fig. 3A3). Further increasing the stimulation intensity elicited a somatic $\mathrm{AP}$ and calcium elevation in all visible compartments of the cell (Fig. 3A4). These AP-evoked calcium transients were very similar to those evoked by somatic current injection (Fig. 3, compare $A 4, A 2)$.

Local synaptic stimulation was effective at evoking calcium transients in 15 AOB mitral cells. Twelve of these cells showed synaptically evoked calcium transients (average peak, $\Delta F / F=$ $0.32 \pm 0.05 ; n=12$ ) (Fig. $3 A 3, B-E$ ) in the tuft that were accompanied by subthreshold EPSPs (peak amplitude, $8.2 \pm 4.0$ ) recorded at the soma. In these cases, calcium transients were not observed in proximal dendrites [ratio of proximal $(>100 \mu \mathrm{m}$ from the tuft) to tuft calcium transients, $7 \pm 6 \% ; n=9$ cells in which tuft and proximal dendritic transients were measured simultaneously; $p<0.02$; paired $t$ test] (Fig. $3 E$ ). We refer to these events as tuft spikes. In the remaining three of 15 cells, all calcium transients observed in tufts were associated with somatic APs (data not shown). These tufts may be less electrically isolated from the soma, facilitating the initiation of somatic APs.

In seven of the 12 cells that showed tuft spikes, higher amplitude extracellular stimulation elicited a somatic AP accompanied by a global calcium influx (ratio of proximal to tuft calcium transients, $77 \pm 18 \% ; n=7 ; p>0.05$ ) (Fig. $3 E, A 4$ ). In the other five of the 12 cells in which tuft spikes were recorded, single-pulse stimulation of the imaged tuft evoked EPSPs but was insufficient to elicit a somatic spike, even when stimulation intensities up to 1 $\mathrm{mA}$ were used (data not shown). In all these cells, sodium spikes and accompanying global calcium elevations could be elicited by somatic current injection (Fig. 3A2) (see above). The inability of our synaptic activation to elicit somatic sodium spikes in some cells may reflect the greater electrically isolation of these tufts from the soma, or it may reflect the fact that these tufts receive relatively weak synaptic input.

We next examined the uniformity of calcium elevation in tufts that was evoked by synaptic stimulation. The average fractional difference between the smallest and the largest branch calcium transients was $75 \pm 12 \%$ ( $n=5$ pairs of branches from five cells) (Fig. 4A2,B). However, in these same cells, backpropagating APs resulted in uniform invasion (average fractional difference between the same branches, $12 \pm 12 \% ; n=5$ branches in five cells) (Fig. 4A4,B). This difference between the spread of AP-evoked versus synaptically evoked calcium transients was significant $(p<0.05$; paired $t$ test) and suggests that different sorts of regenerative events are responsible for the calcium influx evoked by these different stimuli. Moreover, it indicates that subcompartments of AOB mitral cell tufts may be functionally isolated.

Because locally isolated calcium events in dendrites of other 

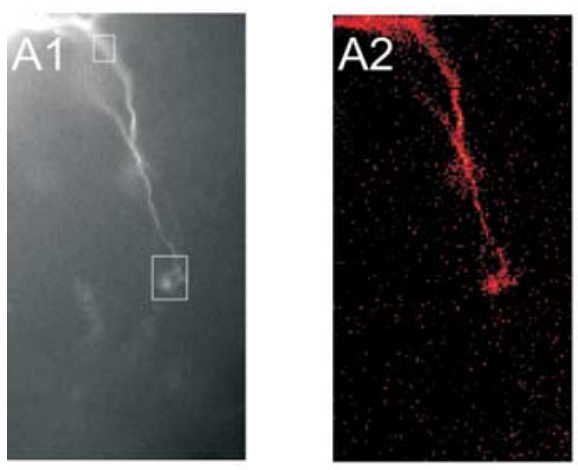

B
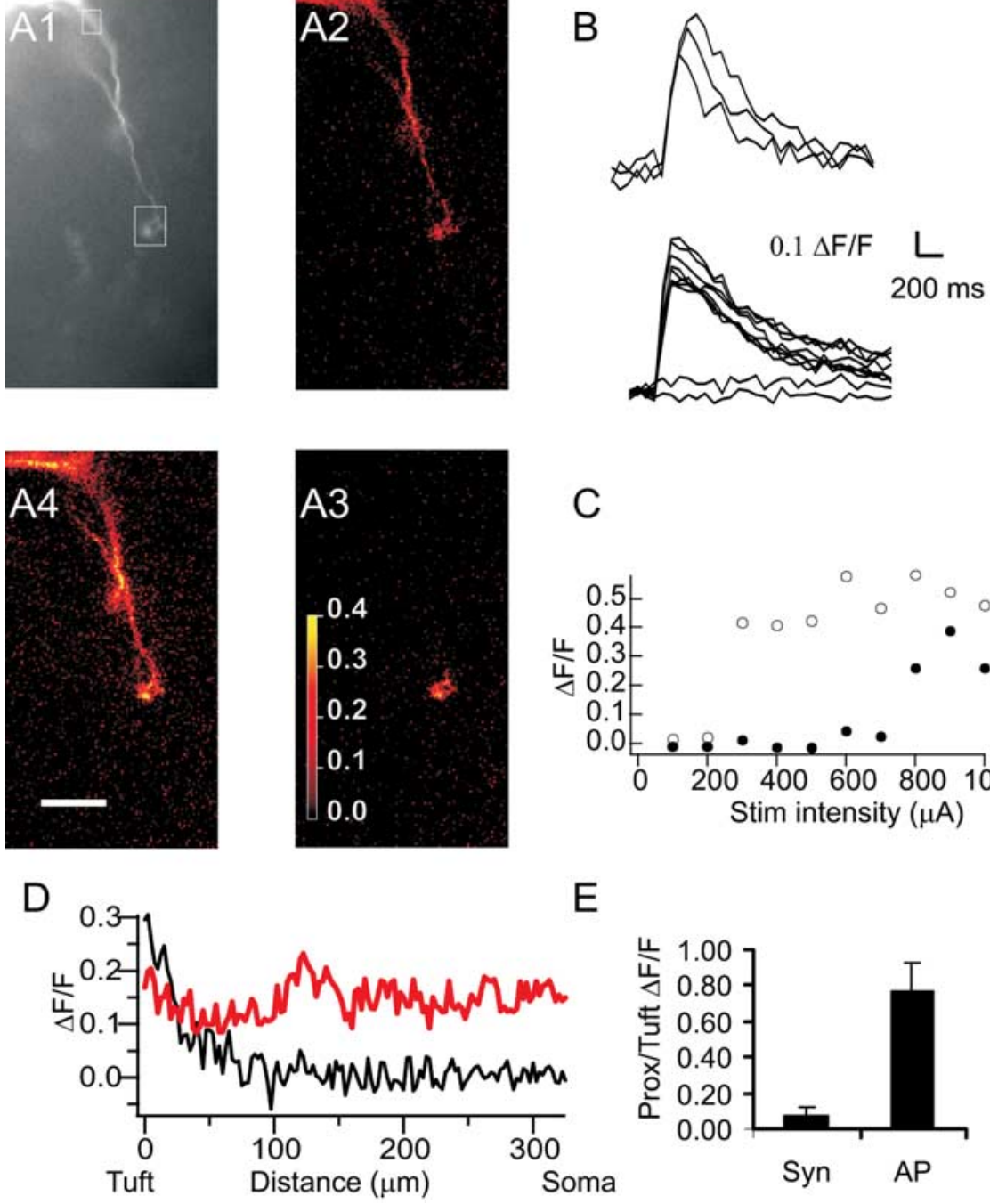

Figure 3. Synaptically evoked calcium transients. A1, Fluorescence image ( $20 \times$ objective) of the dendritic tree of an $A 0 B$ mitral cell. The boxes show regions of interest from which data in $B$ and $C$ are taken. $A 2-A 4, \Delta F / F$ maps of calcium transients evoked in this cell by a single backpropagating AP evoked by somatic current injection (A2) and by low- (A3) or high- (A4) intensity extracellular stimulation of synaptic input to one tuft. $\boldsymbol{B}$, The traces show calcium transients evoked by three consecutive backpropagating APs (top traces) or by extracellular stimulation of varying intensities (as in C, bottom traces). C, Plot of peak $\Delta F / F$ at the tuft (open circles) and at the proximal dendrite (filled circles) as a function of stimulation (Stim) intensity. Low-intensity stimulation evoked no response. Higher-intensity stimulation (corresponding to $\mathbf{A 3}$, above) evoked a transient in the tuft (open circles), whereas the highest intensity stimulation (corresponding to A4, above) evoked a somatic AP and both tuft and somatic (closed circles) calcium transients. Scale bar, $50 \mu \mathrm{m}$. D, Plot of $\Delta$ F/F as a function of distance from the soma for tuft spike (black; A3) versus single backpropagating AP (red; $A 2$ ). E, Average ratio of proximal (Prox) to tuft calcium transients in A0B mitral cells during tuft spikes $(n=9)$ and single backpropagating APs ( $n=7$ of these 9 cells). Syn, Synaptic. Error bars represent SEM.

cell types seem to depend on NMDA receptor activation (Wei et al., 2001; Polsky et al., 2004), we tested to see whether these events were blocked by application of the NMDA receptor blocker APV $(50 \mu \mathrm{M})$. Addition of APV resulted in substantial, but incomplete, reduction in the amplitude of isolated calcium transients in the mitral cell tufts ( $23 \pm 16 \%$ of control; $n=6 ; p<0.05$ ) (Fig. $4 B 1)$. By increasing the stimulation intensity, we were able to partially restore the amplitude of tuft calcium transients $(75 \pm 16 \%$ of control; $n=4 ; p<0.05)$. In contrast, tuft calcium transients evoked by backpropagating spikes were unaffected by addition of APV $(91 \pm 8 \%$ reduction; $p>0.3 ; n=10)$ (Fig. 4 B2). This lack of effect indicates that single backpropagating spikes probably do not result in significant autoexcitation of tuft NMDARs (Carlson et al., 2000; Salin et al., 2001; Urban and Sakmann, 2002).

\section{Discussion}

Summary

We have analyzed the biophysical properties of the primary dendrites and dendritic tufts of AOB mitral cells. Although morphology and passive membrane properties predict that tufts will be electrically isolated from the soma, our calcium-imaging data suggest that these cells support unattenuated backpropagation of APs and local regenerative events when activated by synaptic input. These local regenerative events, or tuft spikes, are reduced by NMDAR blockade and may contribute substantially to the integration of pheromonal information in the accessory olfactory system.

\section{Comparison to other dendrites}

The properties that we describe for $\mathrm{AOB}$ dendrites are similar to those reported for the primary dendrites of main olfactory bulb (MOB) mitral cells and also to those seen for basal dendrites and small apical branches in pyramidal cells. As has been observed in dendritic patch-clamp recordings (Bischofberger and Jonas, 1997; Chen et al., 1997; Margrie et al., 2001; Ma and Lowe, 2004) and calcium-imaging experiments (Charpak et al., 2001; Margrie et al., 2001; Ma and Lowe, 2004) from primary dendrites of other mitral cells, single backpropagating APs cause uniform calcium elevations from soma to tuft in $\mathrm{AOB}$ mitral cell primary dendrites. Isolated dendritic spikes have been observed in tufts of main olfactory bulb mitral cells, but only when somatic spikes were prevented by somatic hyperpolarization, either via direct current injection or activation of inhibitory inputs (Chen et al., 1997; Shen et al., 1999). Here, we observed that after synaptic stimulation, tufts of many AOB mitral cells readily fire isolated tuft spikes without initiating somatic APs. This apparent difference between the properties of mitral cells in these two structures may be attributable to biophysical differences in the properties of MOB and AOB mitral cells, such as the smaller diameter (and thus higher resistance) of AOB mitral cell primary dendrites. However, because the tuft spikes that we observe are mediated in part by NMDAR activation, evoking them with dendritic current injection alone, as was done in most of the experiments on MOB mitral cells, may be difficult.

The tuft spikes that we observe in AOB mitral cells also have many properties in common with NMDA spikes (Schiller et al., 2000; Polsky et al., 2004) and other isolated dendritic events seen in pyramidal cells (Golding and Spruston, 1998; Wei et al., 2001). Tuft spikes in AOB mitral cells seem to depend critically on NMDAR activation, like similar phenomena observed in cortical pyramidal cells (Schiller et al., 2000; Wei et al., 2001). The time course of tuft spikes differs somewhat from that of local dendritic 
spikes in other neurons in that the largest calcium transients are associated with a rapid decay (Fig. 4) rather than a prolonged depolarization (Golding et al., 1999). This may be caused by activation of local circuit interneurons by dendritic release of glutamate from mitral cell tufts. Such a mechanism of local recruitment of tuft release may be an important function of local spikes in AOB (and perhaps also $\mathrm{MOB})$ mitral cell tufts

\section{References}

Belluscio L, Koentges G, Axel R, Dulac C (1999) A map of pheromone receptor activation in the mammalian brain. Cell 97:209-220.

Bischofberger J, Jonas P (1997) Action potential propagation into the presynaptic dendrites of rat mitral cells. J Physiol (Lond) 504:359-365.

Carlson GC, Shipley MT, Keller A (2000) Longlasting depolarizations in mitral cells of the rat olfactory bulb. J Neurosci 20:2011-2021.

Charpak S, Mertz J, Beaurepaire E, Moreaux L, Delaney K (2001) Odor-evoked calcium signals in dendrites of rat mitral cells. Proc Natl Acad Sci USA 98:1230-1234.

Chen WR, Midtgaard J, Shepherd GM (1997) Forward and backward propagation of dendritic impulses and their synaptic control in mitral cells. Science 278:463-467.

Del Punta K, Leinders-Zufall T, Rodriguez I, Jukam D, Wysocki CJ, Ogawa S, Zufall F, Mombaerts P (2002a) Deficient pheromone responses in mice lacking a cluster of vomeronasal receptor genes. Nature 419:70-74.

Del Punta K, Puche A, Adams NC, Rodriguez I, Mombaerts P (2002b) A divergent pattern of sensory axonal projections is rendered convergent by second-order neurons in the accessory olfactory bulb. Neuron 35:1057-1066.

Dulac C, Torello AT (2003) Molecular detection of pheromone signals in mammals: from genes to behaviour. Nat Rev Neurosci 4:551-562.

Golding NL, Spruston N (1998) Dendritic sodium spikes are variable triggers of axonal action potentials in hippocampal CA1 pyramidal neurons. Neuron 21:1189-1200.

Golding NL, Jung HY, Mickus T, Spruston N (1999) Dendritic calcium spike initiation and repolarization are controlled by distinct potassium channel subtypes in CA1 pyramidal neurons. J Neurosci 19:8789-8798.

Hegde AN (2003) MHC molecules in the vomeronasal organ: contributors to pheromonal discrimination? Trends Neurosci 26:646-650.

Hines ML, Carnevale NT (2001) NEURON: a tool for neuroscientists. Neuroscientist 7:123-135

Holy TE, Dulac C, Meister M (2000) Responses of vomeronasal neurons to natural stimuli. Science 289:1569-1572.

Leinders-Zufall T, Lane AP, Puche AC, Ma W, Novotny MV, Shipley MT, Zufall F (2000) Ultrasensitive pheromone detection by mammalian vomeronasal neurons. Nature 405:792-796.

Leypold BG, Yu CR, Leinders-Zufall T, Kim MM, Zufall F, Axel R (2002) Altered sexual and social behaviors in trp2 mutant mice. Proc Natl Acad Sci USA 99:6376-6381.

Lin DM, Wang F, Lowe G, Gold GH, Axel R, Ngai J, Brunet L (2000) Formation of precise connections in the olfactory bulb occurs in the absence of odorant-evoked neuronal activity. Neuron 26:69-80.

Luo M, Fee MS, Katz LC (2003) Encoding pheromonal signals in the accessory olfactory bulb of behaving mice. Science 299:1196-1201.

Ma J, Lowe G (2004) Action potential backpropagation and multiglomerular signaling in the rat vomeronasal system. J Neurosci 24:9341-9352.

Margrie TW, Sakmann B, Urban NN (2001) Action potential propagation in mitral cell lateral dendrites is decremental and controls recurrent and

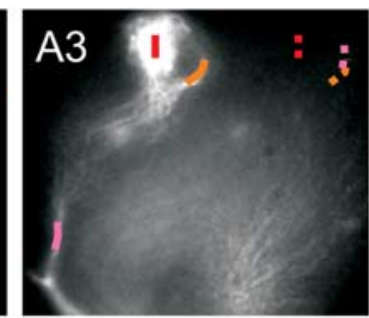

B1
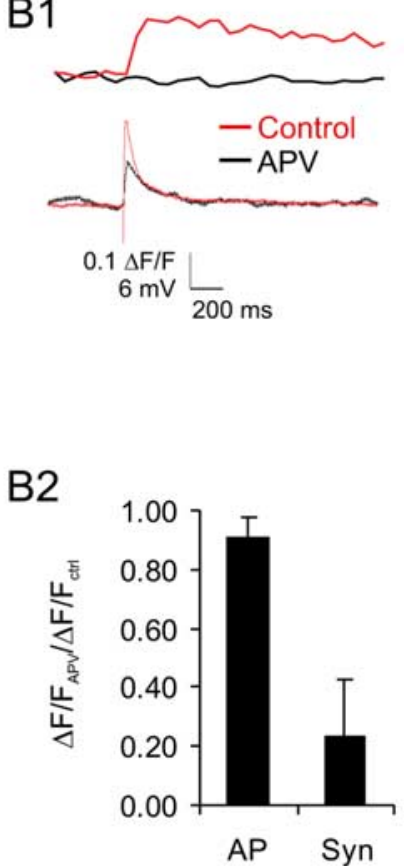

Figure 4. Tuft spikes can cause nonhomogenous activation of tuft branches and are reduced by NMDAR blockade. $\boldsymbol{A}$ 1-A4, The S shows fluorescence images of tuft of an $A O B$ mitral cell with color map selected to highlight one branch on the transients (top traces) and simultaneously recorded voltage traces (bottom) from this same cell show reduction by APV. Synaptic. Error bars represent SEM.

lateral inhibition in the mammalian olfactory bulb. Proc Natl Acad Sci USA 98:319-324.

Polsky A, Mel BW, Schiller J (2004) Computational subunits in thin dendrites of pyramidal cells. Nat Neurosci 7:621-627.

Rodriguez I, Feinstein P, Mombaerts P (1999) Variable patterns of axonal projections of sensory neurons in the mouse vomeronasal system. Cell 97:199-208.

Salin PA, Lledo PM, Vincent JD, Charpak S (2001) Dendritic glutamate autoreceptors modulate signal processing in rat mitral cells. J Neurophysiol 85:1275-1282.

Schiller J, Major G, Koester HJ, Schiller Y (2000) NMDA spikes in basal dendrites of cortical pyramidal neurons. Nature 404:285-289.

Shen GY, Chen WR, Midtgaard J, Shepherd GM, Hines ML (1999) Computational analysis of action potential initiation in mitral cell soma and dendrites based on dual patch recordings. J Neurophysiol 82:3006-3020.

Stowers L, Holy TE, Meister M, Dulac C, Koentges G (2002) Loss of sex discrimination and male-male aggression in mice deficient for TRP2. Science 295:1493-1500.

Stuart G, Spruston N (1995) Probing dendritic function with patch pipettes. Curr Opin Neurobiol 5:389-394.

Takami S, Graziadei PP (1991) Light microscopic Golgi study of mitral/ tufted cells in the accessory olfactory bulb of the adult rat. J Comp Neurol 311:65-83.

Urban NN, Barrionuevo G (1998) Active summation of excitatory postsynaptic potentials in hippocampal CA3 pyramidal neurons. Proc Natl Acad Sci USA 95:11450-11455.

Urban NN, Sakmann B (2002) Reciprocal intraglomerular excitation and intra- and interglomerular lateral inhibition between mouse olfactory bulb mitral cells. J Physiol (Lond) 542:355-367.

Wei DS, Mei YA, Bagal A, Kao JP, Thompson SM, Tang CM (2001) Compartmentalized and binary behavior of terminal dendrites in hippocampal pyramidal neurons. Science 293:2272-2275. 